\title{
探析水电厂电气设备故障检修及其维护
}

\author{
李梦雅 \\ 新疆维吾尔自治区乌鲁瓦提水利枢纽管理局 \\ DOI:10.32629/hwr.v3i6.2238
}

[摘 要] 水电厂中的电气设备一直处于长时间运行的工作状态下, 因受到各种因素的影响, 如人员操作不当、检修人员判断失 误、检修方法不合理等, 都会使得电气设备发生各种故障, 这不仅会阻碍系统的正常运转, 严重时还会给工作人员带来生命威 胁。因此需要加强对电气设备的检修和养护, 及时处理设备运行中存在的故障问题, 以此来保证水电厂的安全稳定运行。本文 就主要对水电厂电气设备故障检修和维护进行分析阐述。

[关键词] 水电厂; 电气设备; 故障检修和维护

水电站电气设备的运行维护与故障检修, 对于水电站的 可靠运行、效益发挥具有举足轻重的作用, 因此应充分重视并 加强这项工作而不是削弱它。文章分析了水电站电气设备运 行维护的方法, 并结合实例探讨了故障检修方面的一些特点。

\section{1 水电厂电气设备故障检修}

水电站电气设备是水电站一次设备和二次设备的统称。 一次设备是直接参与电能生产与分配的设备, 包括发电机、 主变压器、开关设备、母线、电缆、互感器、电抗器、避雷 器等电气设备。二次设备主要是对一次设备(也包括机械设 备、水工建筑物) 进行监测、保护与控制作用的电气设备, 如继电保护装置、自动控制设备、各种电气仪表及信号、控 制电缆等。

\section{1变压器故障检修 \\ 1. 1 . 1 油位异常}

油位过高或过低都会导致变压器运行出现异常。导致油 位过高的原因主要有冷却器堵塞或加油太多, 这时需要将多 余的油清除, 并将存在的杂质清理干净; 当油位过低时, 则需 要工作人员尽快进行油量的补充, 以免阻碍机器运转。

\section{1.2 铁芯过热}

铁芯对变压器的机械强度及电磁性能有着直接影响。在 变压器运转中, 导致铁芯过热的原因相对较多, 如绕组短路、 铁芯接地故障、电源电压过高、铁芯叠片故障灯。在处理过 程中, 需要先对导致铁芯过热的原因予以明确, 有针对性的 开展检修工作。铁芯过热的处理措施主要有以下几种: 利用 干毛巾将铁芯表面的油污清理干净; 检修绝缘设备, 避免绕 组短路带来影响; 检查接地装置, 并对其中存在故障的零部 件予以更换。

\section{1.3 局部放电}

变压器在正常运转过程中, 或多或少都会存在一些放电 现象, 只要放电量在规定的范围内就不会对变压器及周边机 器设备造成影响。

\section{2 高压配电装置故障检修}

高压配电装置故障主要是断路器设备出现拒跳或拒合 现象而导致电能输送出现异常。当拒跳现象产生时, 系统中
的信号灯和回路红灯会同时闪炼, 这时工作人员可通过手动 拉闸的方式, 对断路器接触位置进行检查, 解决拒跳问题带 来的影响; 当拒合现象发生时, 需要在合闸后, 对控制电源予 以检查, 查看其保险丝有无烧坏情况, 电压互感器是否存在 熔断故障灯。如果是熔断器问题, 要再进一步实行检查, 确定 是由于铁芯饱和现象导致的问题还是由于系统谐振过电压 问题而引发的故障, 然后采取合理方式加以解决。

\section{3 发电机组故障检修}

1.3.1欠电压现象

欠电压现象产生原因: 在发电过程中, 励磁装置出现复励 不足的情况, 进而降低励磁电流传输效果, 引起欠电压现象。

影响: 欠电压现象会导致发电机运行不在额定电压范围 内, 进而降低电能的传输效率。

检修措施: 一是在发电机和励磁电抗器中间位置上安装 三相调压器, 通过该设备对电压和励磁电流予以调整, 增强 电流的平衡性; 二是降低变阻器组织, 通过电容补偿方式提 高励磁电流。

\section{3.2 发电机温度上升过高}

造成发电机温度上升过高的原因: 电负荷或定转子的电 流负荷存在异常, 发电机温度明显升高; 通风系统异常导致 发电机温度升高。在故障检修过程中, 工作人员需根据故障 产生原因制定合理的解决措施。在处理因电负荷或定转子电 流负荷过高而导致的异常现象时, 一般会先对发电机的电负 荷实行准确测量, 准确计算出热负荷情况, 制定合理的控制 和降低措施; 在解决因通风系统而导致的温度过高问题时, 则需要进行转子圈的更换, 使用截面较大的转子圈来降低电 流密度, 降低发电机温度。另外, 在通风系统引发的故障问题 处理上, 还可以通过风扇及挡板的改造来加快散热, 或者通 过增加磁极风量来强化散热效果。前者在实际工作中, 因检 修成本较低, 工作量较少, 应用的范围相对较广。

\section{3. 3绝缘故障}

绝缘故障的产生大多是由于主绝缘破坏以及转子绝缘 破坏引起的。在主绝缘检查时, 需要对铁芯予以重点关注, 一旦发现铁芯存在松动、腐蚀等问题要及时处理。而判断铁 
芯松动和腐蚀的主要依据为: 铁芯上出现红色粉末说明其存 在松动现象; 检查铁芯过程中, 能够闻到臭氧味, 则说明其存 在腐蚀问题。在转子绝缘检查时, 需要进行转子绝缘电阻的 测量, 如果发现其电阻值趋近于零, 则说明其存在故障。

转子绝缘故障的原因主要有两种: 一是励磁系统的直流 和交流设备故障; 二是出现二次接地现象。检修过程中, 应 对存在破坏的电缆予以重新包扎, 或者增加励磁电流。

\section{2 水电厂电气设备的维护}

2.1 常规检查

对于水电厂的电气设备来说, 常规检查大多是以现场巡 查的方式开展的, 这种方式能够让工作人员第一时间发现电 气设备存在的故障, 并及时开展相应的检修和维护。不过巡 查作业消耗的人力相对较大, 工作量较重。所以在现今水电 厂电气设备维护中, 需要通过不同维护方式的综合运用来提 升设备的安全运行效果。一方面, 工作人员可通过巡查来判 定设备的运行状态, 一旦发现故障问题, 要及时予以鉴别和 上报; 另一方面, 在设备巡查过程中, 应调动工作人员的听 觉、嗅觉和视觉来判断设备的运转状态。观察设备各部件的 运转情况、听设备运转时发出的声音状况, 嗅设备运行时是 否存在特殊气味, 综合分析和判定电气设备情况, 降低故障 的影响。

巡查工作完成后, 不管设备有无故障, 工作人员都要实 行检查维护工作的详细记录, 以此来为后续工作的开展提供 依据。此外, 在现今科技发展过程中, 电子监控系统在水电厂 设备检修和维护中得到了广泛应用, 该系统的使用不仅实现 了电气设备的实时监控, 同时也降低了人力方面的损耗, 管 理人员只需通过计算机技术的操作即可及时掌握电气设备 的运行状况, 及时处理存在的故障问题。

再者, 系统自身也具有自动监控和报警的功能, 能够将 存在的故障问题及时上报, 并指出故障位置, 提高检修和维 护作业的效率, 减少危险的发生。不过在使用电子监控系统 时, 应注重其与人工检查的配合, 以此来提升电气设备故障 笁查的灵活性和及时性, 加强细节处理。例如一些本不属于 故障问题, 但对电气设备正常运转存在极大威胁的散热口存 在大量灰尘堆积、机壳中存在诸多杂物等。因此, 在检查电 气设备的过程中, 工作人员的定期检查还是必不可少的。

2. 2 确保电气设备操作的规范性

设备操作的规范性是避免故障发生, 促进系统正常运行 的基础。因此, 企业有必要建立完善的电气设备操作规范流 程及控制标准, 约束工作人员的操作行为, 做好定期的检修
和维护工作。在实际作业中, 一方面要加大对设备操作人员 的培训力度, 让其熟练掌握电气设备操作的标准要求和规范, 并在后续工作中, 不断丰富操作人员的知识储备。另一方面, 加大监管力度, 切勿随意性操作或私自更改电气设备运行指 标, 降低失误率, 增强设备安全性。

另外, 对于操作失误或不规范操作行为的员工要给与严 万处理, 禁止类似事件的发生, 延长电气设备的使用寿命。在 操作完成后, 要及时将设备状况与操作过程记录下来, 且现 场所有管理人员与操作人员需签字确认, 为今后的的操作提 供理论依据。

\section{3 日常维护}

以变压器和发电机的日常维护为例, 变压器在日常维护 中需要检查的项目相对较多, 如接地保护、防雷措施、铁芯 的绝缘保护层质量、变压器的运行状态等。一旦发现问题, 工作人员要及时采取有效的防护措施, 维护变压器安全运行, 减少对周边人和物的影响。发电机的日常维护首要工作就是 做好设备的清洁工作, 及时清理设备中堆积的尘埃、杂物等。 清理过程中尽量避免直接接触设备, 这样不仅能够减少对设 备的二次污染, 延缓设备老化, 同时还能够保障操作人员的 人身安全。之后再对电机上的滑环和电刷进行维护, 让电刷 处在滑环的中心位置。最后对接地保护装置、相关设备予以 检查, 及时排除其中存在的安全隐患, 增强发电机的安全性。

\section{3 结束语}

综上所述, 随着经济技术的不断发展, 我国的水电厂自 动化程度越来越高, 并成为电力的主要来源。但因为水电厂 涉及的电气设备较多, 且体型较大, 故而设备故障检修及其 维护也存在一定的难度, 基于此, 为了最大程度的保障电气 设备的高效稳定运行, 就需要加强对其关注力度, 以此来更 好的保障水电厂的稳定运行。

\section{[参考文献]}

[1]沙海丁・赛德尔丁.水电站电气设备运行维护与故障 检修分析[J].内蒙古水利,2018,(01):79-80.

[2]江东伟.水电站电气设备运行维护与故障检修 [J].建 材与装饰,2018,(32):262-263.

[3] 曾三.关于水电厂电气设备长周期运行措施分析 [J]. 山东工业技术,2017,(17):173。

[4]雷清淞.新时期水电厂电气设备的特点以及长周期运 行措施探讨 [J].智能城市,2018,4(13):108-109.

[5]夏江庭.关于水电厂电气设备长周期运行措施的探讨 [J].通讯世界,2016,(17):225-226。 